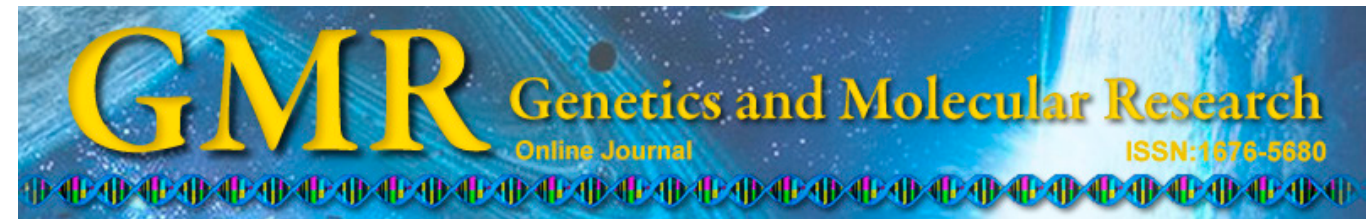

\title{
Association between V4 polymorphism in the $A D A M 33$ gene and asthma risk: a meta-analysis
}

\author{
W. Zheng, L. Wang, X. Su and X.F. Hu \\ Department of Laboratory Medicine, \\ The General Hospital of Shenyang Military Region, Shenyang, China \\ Corresponding author: X.F. Hu \\ E-mail: syjqzyy_hxf@126.com \\ Genet. Mol. Res. 14 (1): 989-999 (2015) \\ Received November 22, 2013 \\ Accepted April 10, 2014 \\ Published February 6, 2015 \\ DOI http://dx.doi.org/10.4238/2015.February.6.2
}

\begin{abstract}
In this study, we evaluated the associations between the V4 (rs2787094 G>C) polymorphism in a disintegrin and metalloproteinase domain 33 (ADAM33) gene and asthma risk. We searched Web of Science, PubMed, Google Scholar, EBSCO, Cochrane Library, and CBM databases from inception through August 2013, without language restrictions. Meta-analysis was performed using the STATA 12.0 software. Crude odds ratios and 95\% confidence intervals were calculated. Eight case-control studies were included, with a total of 2128 asthma patients and 3134 healthy controls. Our results suggest that the ADAM33 V4 polymorphism increases the risk of asthma. Subgroup analysis according to the source of controls revealed significant associations between the ADAM33 V4 polymorphism and risk of asthma in population- and hospital-based subgroups under allele and dominant models (all $\mathrm{P}<0.05$ ). Further subgroup analysis using the genotyping method suggested that the ADAM33 V4 polymorphism is correlated with asthma risk in the polymerase chain reaction-restriction fragment length polymorphism subgroup. However, no association was found in the non-polymerase chain reaction-restriction fragment length polymorphism subgroup. Meta-regression analyses showed that the genotyping method may be a main source of heterogeneity $(\mathrm{P}=0.003)$. Our meta-analysis suggests that the ADAM33 V4 polymorphism
\end{abstract}


contributes to the risk of asthma and may be utilized as a biomarker for the early diagnosis of asthma.

Key words: ADAM33; Asthma; Polymorphism; Meta-analysis

\section{INTRODUCTION}

Asthma, which is characterized by bronchial hyper-responsiveness and chronic bronchial inflammation, is a chronic inflammatory disorder of the conducting airways (Holgate, 2008). According to recent epidemiological studies, asthma is becoming one of the most prevalent diseases in developing countries, mainly occurring in children, females, and black persons (Liang et al., 2013). Approximately 300 million people are affected by asthma, causing nearly 180,000 deaths each year worldwide (Akinbami et al., 2012). Generally, asthma is recognized as a multi-factorial disease induced by complex interactions between environmental and genetic factors (Tsicopoulos et al., 2013). Various intrinsic and extrinsic risk factors for asthma have been established, including allergenic exposure, pollutants, tobacco, and aerosol exposure among others; however, the causes of asthma are complex and not well-understood (Louis et al., 2012). Because individuals of different genetic backgrounds show varying susceptibilities to asthma, molecular genetic factors are thought to play a crucial role in asthma pathogenesis (Blumenthal, 2012).

A disintegrin and metalloproteinase 33 (ADAM33) belongs to a multifunctional family of a disintegrin and metalloproteinase considered to be multi-domain proteins with metalloprotease-like, epidermal growth factor-like, and cytoplasmic domains (Hodgkinson et al., 2010; Klein and Bischoff, 2011). In recent decades, ADAM33 has been shown to have a positive effect on cell signaling, cell adhesion, cell fusion, and proteolysis (Knutsen and Slavin, 2011). Moreover, several experiments have suggested its important role in activating growth factors and Th2 cytokines (Reiss and Saftig, 2009). The human ADAM33 gene, which is located on chromosome 20p13 and spans approximately $14 \mathrm{~kb}$, contains 22 exons and $21 \mathrm{in}-$ trons and encodes a protein of 813 amino acids (Deloukas et al., 2001). ADAM33 is typically expressed in human lung fibroblasts and bronchial smooth muscle cells. Thus, alterations in ADAM33 activity may alter the function of these cells, leading to airway remodeling (Holgate et al., 2006; Liang et al., 2013). Importantly, bronchial hyper-reactivity and airway obstruction induced by the presence of airway remodeling is closely correlated with asthma (Lambrecht and Hammad, 2012). Numerous studies have proposed that a common polymorphism (V4, rs $2787094 \mathrm{G}>\mathrm{C}$ ) in the $A D A M 33$ gene is significantly related to asthma susceptibility (Tripathi et al., 2011; Awasthi et al., 2011; Qu et al., 2011). However, the results are conflicting, and some studies indicate that there is no association between the ADAM33 V4 polymorphism and asthma risk (Bijanzadeh et al., 2010; Qu et al., 2011). To resolve these conflicting results, we performed a meta-analysis to examine the association between the ADAM33 V4 polymorphism and asthma development.

\section{MATERIAL AND METHODS}

\section{Literature search strategy}

We searched Web of Science, PubMed, Google Scholar, EBSCO, Cochrane Library, 
and CBM databases from inception through August 2013, without language restrictions. The following key words and MeSH terms were used: ["SNP" or "mutation" or "genetic polymorphism" or "variation" or "polymorphism" or "single nucleotide polymorphism" or "variant"] and ["asthma" or "bronchial asthma" or "AMA") and ["a disintegrin and metalloprotease 33" or "ADAM33"]. We also performed a manual search to identify other potential articles.

\section{Selection criteria}

Studies included in the meta-analysis had to meet all of the following criteria: 1) the study design must be a clinical cohort or case-control study; 2) the study must be related to the relationship between the $A D A M 33 \mathrm{~V} 4$ polymorphism and asthma risk; 3) all the patients must conform to the diagnostic criteria for asthma; and 4) the study must provide sufficient information regarding the frequencies of $A D A M 33 \mathrm{~V} 4$ polymorphism. If a study did not meet the inclusion criteria, it was excluded from analysis. When authors published multiple studies using the same subjects, either the most recent or the study with the largest sample size was included.

\section{Data extraction}

Using a standardized form, relevant data were systematically extracted by two researchers from all the included studies. The standardized form included the following items: language of publication, publication year of the article, the first author's surname, geographical location, design of study, sample size, the source of the subjects, allele frequencies, source of samples, genotyping method of SNP, and evidence of Hardy-Weinberg equilibrium (HWE) in the healthy controls.

\section{Quality assessment}

We evaluated the methodological quality of the included studies using the NewcastleOttawa Scale (NOS) criteria (Stang, 2010). The NOS criteria evaluates 3 aspects: 1) subject selection: 0-4 scores; 2) comparability of subjects: 0-2 scores; and 3) clinical outcome: 0-3 scores. NOS scores range from $0-9$, with a score of $\geq 7$ indicating good methodological quality.

\section{Statistical analysis}

We performed this meta-analysis using the STATA 12.0 software (Stata Corp., College Station, TX, USA). Odds ratios (OR) and their 95\% confidence intervals (CI) were estimated under 5 genetic models: allele model (C allele $v s \mathrm{G}$ allele), dominant model (GC $+\mathrm{CC} v s \mathrm{GG})$, recessive model (CC vs GG $+\mathrm{GC})$, homozygous model (CC vs GG), and heterozygous model (CC vs GC). The Z-test was used to estimate the statistical significance of ORs. Power calculations were conducted using PS Power and Sample Size Calculations (Dupont and Plummer Jr., 1990). The Cochran's $Q$-statisticd test and the $I^{2}$ test were used to evaluate potential heterogeneity between studies (Zintzaras and Ioannidis, 2005). If the $Q$-test resulted in $\mathrm{P}<0.05$ or the $I^{2}$ test of $>50 \%$, indicating significant heterogeneity, the random-effect model was used; otherwise, the fixed-effect model was used. We also performed subgroup and meta-regression analyses to explore the potential sources of heterogeneity. Sensitivity analysis was performed 
by omitting each study in turn to evaluate the influence of single studies on the overall estimate. Funnel plots and the Egger linear regression test were also conducted to investigate publication bias (Peters et al., 2006).

\section{RESULTS}

\section{Characteristics of the studies included}

A total of 118 articles relevant to the searched key words were initially identified. The titles and abstracts of all the articles were reviewed, and 53 articles were excluded. Full texts and data integrity were then reviewed and another 57 papers were excluded. Finally, 8 case-control studies were selected for inclusion in this meta-analysis (Howard et al., 2003; Lee et al., 2004; Su et al., 2008; Awasthi et al., 2011; Qu et al., 2011; Chi et al., 2012; Li et al., 2012; Miyake et al., 2012). The publication years of eligible studies ranged from 2003-2012. The process of selecting eligible studies is shown in Figure 1. The distribution of the amount of topic-related literature in the electronic database over the last decade is shown in Figure 2.

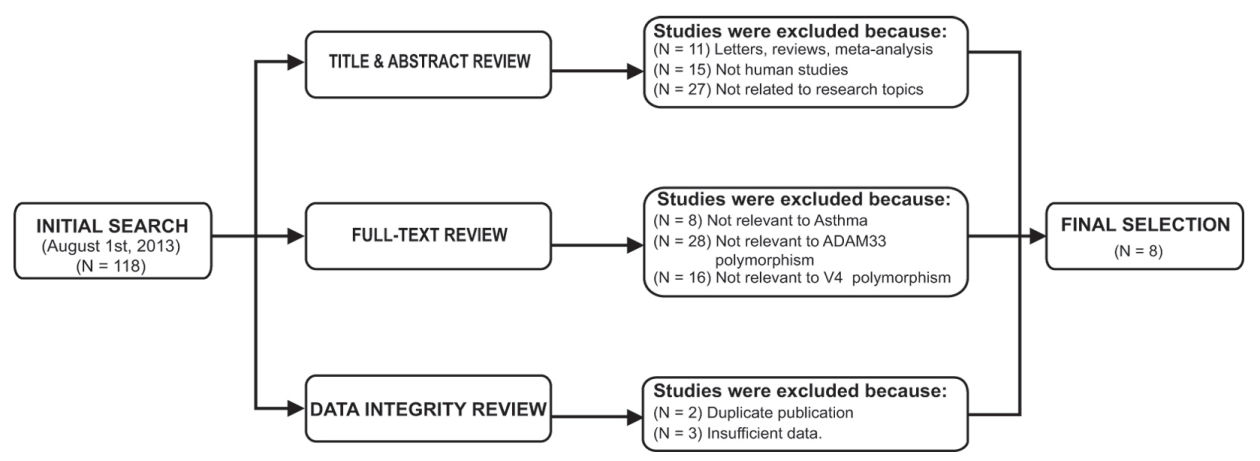

Figure 1. Flow chart of literature search and study selection. Eight case-control studies were included in this metaanalysis.

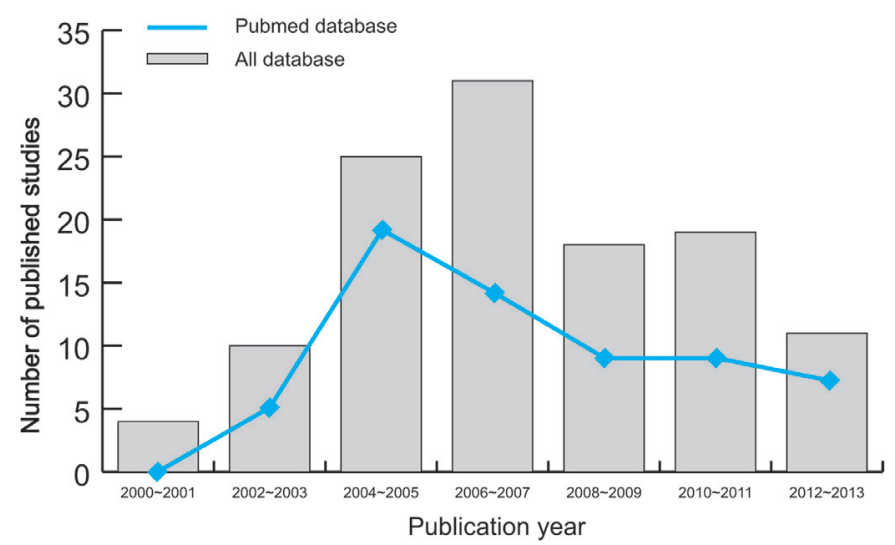

Figure 2. Distribution of topic-related studies in the electronic database. 
A total of 5262 subjects were analyzed in this meta-analysis, including 2128 asthma patients and 3134 healthy controls. The statistical power of the included studies' sample sizes were higher than 0.70. Overall, 7 studies were conducted in Asian populations and 1 study was conducted in a Caucasian population. The polymerase chain reaction-restriction fragment length polymorphism (PCR-RFLP) method was performed in 4 studies, while the other 4 studies used non-PCR-RFLP methods. Genotype frequencies of controls were all in HWE (all P > 0.05). NOS scores of all the included studies were higher than 6 (moderate-high quality). Study characteristics and methodological quality are summarized in Table 1.

Table 1. Main characteristics and methodological quality of all the eligible studies.

\begin{tabular}{|c|c|c|c|c|c|c|c|c|c|c|c|c|c|}
\hline \multirow[t]{2}{*}{ First author } & \multirow[t]{2}{*}{ Year } & \multirow[t]{2}{*}{ Country } & \multirow[t]{2}{*}{ Ethnicity } & \multicolumn{3}{|c|}{ Sample size } & \multicolumn{2}{|c|}{ Gender $(\mathrm{M} / \mathrm{F})$} & \multicolumn{2}{|c|}{ Age (year) } & \multirow{2}{*}{$\begin{array}{l}\text { Genotyping } \\
\text { method }\end{array}$} & \multirow{2}{*}{$\begin{array}{l}\text { HWE test } \\
\text { (P value) }\end{array}$} & \multirow{2}{*}{$\begin{array}{l}\text { NOS } \\
\text { score }\end{array}$} \\
\hline & & & & Case & Control & Power & - Case & Control & Case & Control & & & \\
\hline ni XY & 2012 & Chinese & Asian & 126 & 121 & 0.763 & $67 / 59$ & $68 / 53$ & $39.9 \pm 13.2$ & $43.0 \pm 12.5$ & AS-PCR & 0.071 & 8 \\
\hline Miyake Y & 2012 & Japan & Asian & 89 & 1281 & 0.987 & 0/89 & $0 / 1281$ & $130.4 \pm 4.2$ & $31.5 \pm 4.2$ & TaqMan & 0.196 & 8 \\
\hline Li HB & 2012 & Chinese & Asian & 110 & 144 & 0.772 & $61 / 49$ & - & - & - & PCR-RFLP & 0.396 & 6 \\
\hline Qu S & 2011 & Chinese & Asian & 412 & 397 & 0.959 & $199 / 213$ & $3192 / 205$ & $7.7 \pm 2.8$ & $7.5 \pm 3.0$ & PCR-RFLP & 0.066 & 8 \\
\hline Awasthi S & 2011 & India & Asian & 211 & 137 & 0.897 & $143 / 68$ & $96 / 41$ & $74.4 \pm 45.6$ & $73.61 \pm 42.56$ & 6 PCR-RFLP & 0.088 & 8 \\
\hline Su D & 2008 & Chinese & Asian & 181 & 151 & 0.876 & $114 / 67$ & $97 / 54$ & $36.7 \pm 11.5$ & $37.2 \pm 10.6$ & PCR-RFLP & 0.068 & 7 \\
\hline Lee JH & 2004 & Korea & Asian & 326 & 151 & 0.898 & $131 / 195$ & $580 / 71$ & $48(11-78)$ & $27(10-74)$ & Direct sequencing & g 0.390 & 7 \\
\hline Howard TD & 2003 & Mix & Mix & 673 & 752 & 0.993 & - & - & - & - & MassArray & 0.211 & 6 \\
\hline
\end{tabular}

$\mathrm{AS}=$ allele-specific; $\mathrm{PCR}=$ polymerase chain reaction; $\mathrm{RFLP}=$ restriction fragment length polymorphism; $\mathrm{NOS}=$ Newcastle- $\quad$ Ottawa Scale; $\mathrm{M}=$ male; $\mathrm{F}=$ female

\section{Quantitative data synthesis}

A summary of our findings regarding the associations between the ADAM33 V4 polymorphism and asthma risk is shown in Table 2. The random-effect model was used because of the existence of significant inter-study heterogeneity. The meta-analysis results indicated that the $A D A M 33 \mathrm{~V} 4$ polymorphism increases the risk of asthma (C vs G: OR $=1.58,95 \% \mathrm{CI}: 1.14-2.18, \mathrm{P}=0.006 ; \mathrm{GC}+\mathrm{CC} v s \mathrm{GG}: \mathrm{OR}=1.42,95 \% \mathrm{CI}: 1.25-1.60, \mathrm{P}$ $=0.000$ ) (Figure 3). Subgroup analysis by source of controls showed that there were significant associations between the $A D A M 33 \mathrm{~V} 4$ polymorphism and increased risk of asthma in population-based and hospital-based subgroups (population-based: $\mathrm{OR}=1.58,95 \% \mathrm{CI}$ : 1.06-2.35, $\mathrm{P}=0.024$; hospital-based: $\mathrm{OR}=1.57,95 \% \mathrm{CI}$ : 0.73-3.37, $\mathrm{P}=0.006$ ) (Figure 4). Further subgroup analysis by genotyping method suggested that the ADAM33 V4 polymorphism was correlated with asthma risk in the PCR-RFLP subgroup (C allele $v s \mathrm{G}$ allele: OR $=2.21,95 \%$ CI: 1.44-3.40, P $=0.001 ; \mathrm{GC}+\mathrm{CC} v s \mathrm{GG}: \mathrm{OR}=2.29,95 \% \mathrm{CI}: 1.88-2.78, \mathrm{P}<$ $0.001)$. However, no association was found in the non-PCR-RFLP subgroup (C allele $v s \mathrm{G}$ allele: $\mathrm{OR}=1.07,95 \% \mathrm{CI}: 0.94-1.21, \mathrm{P}=0.314 ; \mathrm{GC}+\mathrm{CC}$ s $\mathrm{GG}: \mathrm{OR}=1.02,95 \% \mathrm{CI}: 0.87$ $1.20, \mathrm{P}=0.769$ ) (Figure 4).

The results of our sensitivity analysis suggest that no single study significantly influenced the overall pooled ORs (Figure 5). Univariate and multivariate meta-regression analyses showed that genotyping method may be a main source of heterogeneity $(\mathrm{P}=$ 0.003; Table 3). We found no clear evidence of asymmetry based on funnel plots (Figure 6). The Egger test also did not display strong statistical evidence of publication bias (C allele $v_{s}$ G allele: $t=-0.59, \mathrm{P}=0.571$; GC+CC $v s \mathrm{GG}: t=-1.39, \mathrm{P}=0.198$ ). 
Table 2. Meta-analysis of the association between the $A D A M 33 \mathrm{~V} 4$ polymorphism and asthma risk.

\begin{tabular}{|c|c|c|c|c|c|c|c|c|c|c|c|c|c|c|}
\hline \multirow[t]{2}{*}{ Subgroups } & \multicolumn{2}{|c|}{$\begin{array}{l}\mathrm{C} \text { allele } v s \mathrm{G} \text { allele } \\
\text { (allele model) }\end{array}$} & \multicolumn{3}{|c|}{$\begin{array}{c}\mathrm{GC}+\mathrm{CC} v s \mathrm{GG} \\
\text { (dominant model) }\end{array}$} & \multicolumn{3}{|c|}{$\begin{array}{l}\mathrm{CC} v s \mathrm{GG}+\mathrm{GC} \\
\text { (recessive model) }\end{array}$} & \multicolumn{3}{|c|}{$\begin{array}{c}\text { CC vs GG } \\
\text { (homozygous model) }\end{array}$} & \multicolumn{3}{|c|}{$\begin{array}{c}\text { CC vs GC } \\
\text { (heterozygous model) }\end{array}$} \\
\hline & OR $95 \% \mathrm{CI}$ & $\mathrm{P}$ & OR & $95 \% \mathrm{CI}$ & $\mathrm{P}$ & OR & $95 \% \mathrm{CI}$ & $\mathrm{P}$ & OR & $95 \% \mathrm{CI}$ & $\mathrm{P}$ & OR & $95 \% \mathrm{CI}$ & $\mathrm{P}$ \\
\hline Overall & $1.371 .10-1.17$ & 0.005 & 1.19 & $1.12-1.26$ & 0.000 & 1.36 & $0.92-2.02$ & 0.121 & 1.54 & $0.95-2.48$ & 0.077 & 1.08 & $0.90-1.29$ & 0.428 \\
\hline \multicolumn{15}{|l|}{ Source of control } \\
\hline Population-based & $1.371 .05-1.79$ & 0.020 & 1.18 & $1.10-1.26$ & 0.000 & 1.30 & $0.81-2.08$ & 0.278 & 1.46 & $0.82-2.59$ & 0.201 & 1.05 & $0.84-1.32$ & 0.649 \\
\hline Hospital-based & $1.390 .78-2.49$ & 0.261 & 1.22 & $1.05-1.40$ & 0.008 & 1.62 & $0.80-3.31$ & 0.181 & 1.91 & $0.68-5.40$ & 0.220 & 1.27 & $0.80-2.01$ & 0.313 \\
\hline \multicolumn{15}{|c|}{ Genotyping method } \\
\hline PCR-RFLP & $1.761 .27-2.43$ & 0.001 & 1.48 & $1.35-1.63$ & 0.000 & 1.93 & $0.82-4.53$ & 0.129 & 2.46 & $0.87-6.95$ & 0.089 & 1.19 & $0.78-1.82$ & 0.410 \\
\hline Non-PCR-RFLP & $1.050 .96-1.14$ & 0.287 & 1.01 & 0.94-1.09 & 0.767 & 1.03 & $0.81-1.31$ & 0.802 & 1.04 & $0.83-1.30$ & 0.753 & 1.02 & $0.81-1.28$ & 0.866 \\
\hline
\end{tabular}

$\mathrm{OR}=$ odds ratios $; 95 \% \mathrm{CI}=95 \%$ confidence interval; $\mathrm{PCR}-\mathrm{RFLP}=$ polymerase chain reaction-restriction fragment length polymorphism

\begin{tabular}{|c|c|c|c|}
\hline Included study & allele versus $\mathbf{G}$ allele & OR $(95 \% \mathrm{Cl})$ & Weight $\%$ \\
\hline Chi XY (2012) & & $1.35(0.91,2.01)$ & 11.74 \\
\hline Miyake Y (2012) & & $1.16(0.85,1.60$ & 12.59 \\
\hline Li HB (2012) & & $2.36(1.56,3.56)$ & 11.61 \\
\hline Qu S (2011) & & $2.19(1.77,2.70$ & 13.46 \\
\hline Awasthi S (2011) & & $1.21(0.86,1.71)$ & 12.34 \\
\hline Su D (2008) & & $4.01(2.67,6.02)$ & 11.68 \\
\hline Lee JH (2004) & & $1.08(0.81,1.45)$ & 12.81 \\
\hline Howard TD (2003) & & $0.99(0.84,1.17)$ & 13.77 \\
\hline Heterogeneity test $\left(l^{2}=90.0 \%, P<0.001\right)$ & & $1.58(1.14,2.18)$ & 100.00 \\
\hline \multicolumn{4}{|l|}{$Z$ test $(Z=2.75, P=0.006)$} \\
\hline \multicolumn{4}{|l|}{ Random effects analysis } \\
\hline 0.166 & + & & \\
\hline
\end{tabular}

\begin{tabular}{|c|c|c|c|}
\hline Included study & $\mathbf{G C}+\mathbf{C C}$ versus $\mathbf{G} \mathbf{G}$ & OR $(95 \% \mathrm{Cl})$ & Weight $\%$ \\
\hline Chi XY (2012) & & $0.86(0.52,1.42)$ & 7.77 \\
\hline Miyake Y (2012) & & $1.20(0.77,1.86)$ & 8.73 \\
\hline Li HB (2012) & & $2.84(1.70,4.76)$ & 4.00 \\
\hline Qu S (2011) & & $2.70(2.03,3.59)$ & 13.53 \\
\hline Awasthi S (2011) & & $0.72(0.46,1.13)$ & 10.71 \\
\hline Su D (2008) & & $5.30(3.17,8.87)$ & 2.95 \\
\hline Lee JH (2004) & & $1.05(0.70,1.56)$ & 11.07 \\
\hline Howard TD (2003) & & $1.01(0.82,1.25)$ & 41.23 \\
\hline Heterogeneity test $\left(l^{2}=90.9 \%, P<0.001\right)$ & & $1.42(1.25,1.60)$ & 100.00 \\
\hline \multicolumn{4}{|l|}{$Z$ test $(Z=5.56, P<0.001)$} \\
\hline \multicolumn{4}{|l|}{ Random effects analysis } \\
\hline 0.113 & & & \\
\hline
\end{tabular}

Figure 3. Forest plots for the association between the $A D A M 33 \mathrm{~V} 4$ polymorphism and asthma risk under the allele and dominant models. 


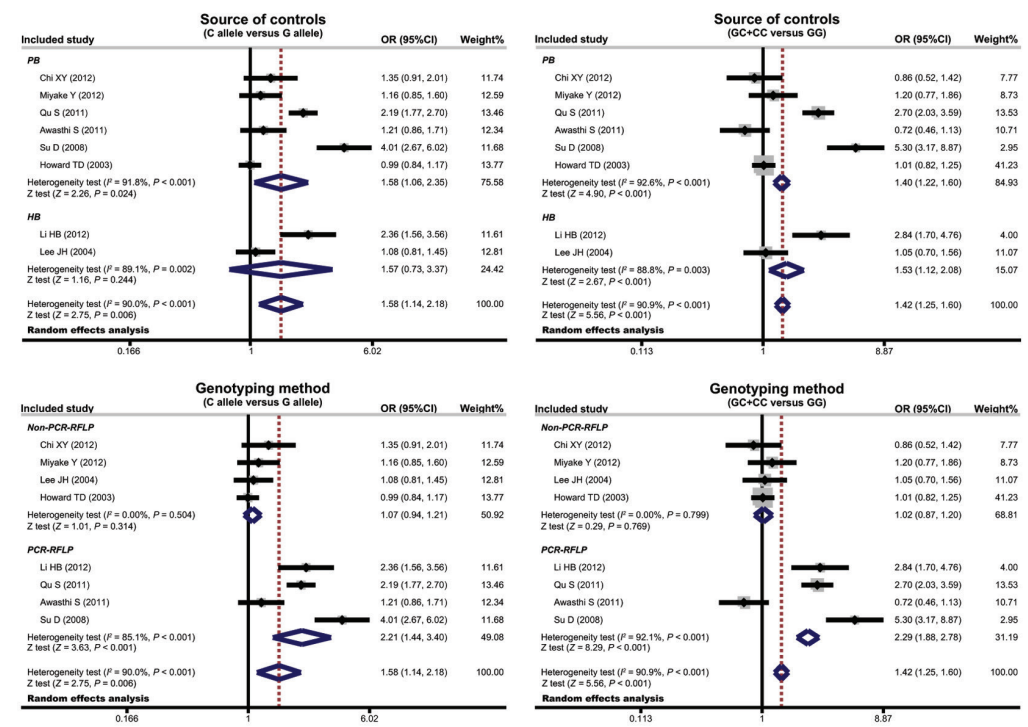

Figure 4. Subgroup analysis by source of controls and genotyping method for the association between the ADAM33 V4 polymorphism and asthma risk under the allele and dominant models.
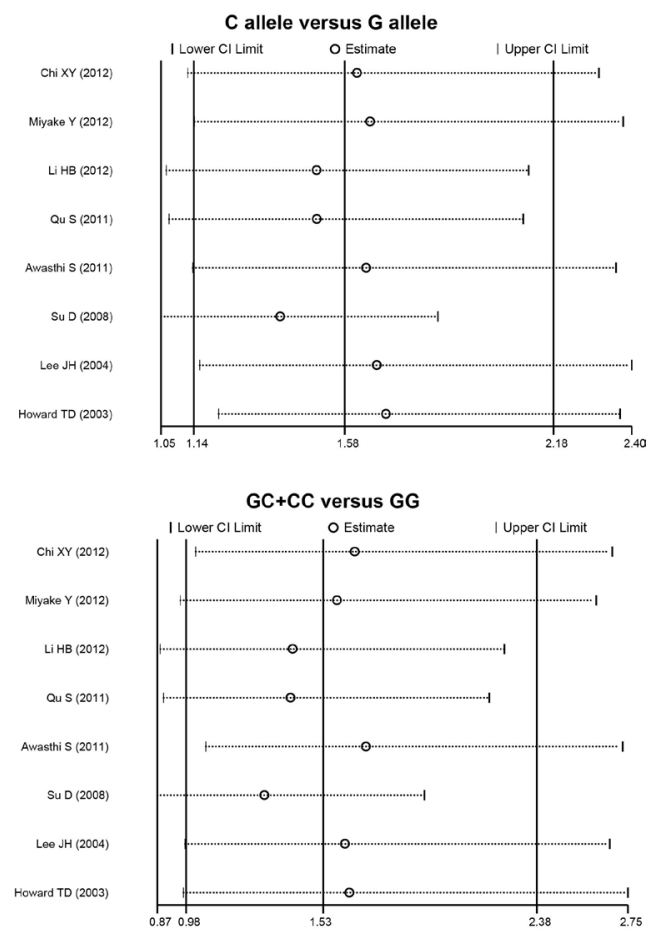

Figure 5. Sensitivity analysis of the summary odds ratio coefficients for the association between the ADAM33 V4 polymorphism and asthma risk under the allele and dominant models. Results were computed by omitting each study in turn. Meta-analysis random-effect estimates (exponential form) were used. The 2 ends of the dotted lines represent the $95 \% \mathrm{CI}$. 
Table 3. Univariate and multivariate meta-regression analyses of potential sources of heterogeneity

\begin{tabular}{|c|c|c|c|c|c|c|}
\hline \multirow[t]{2}{*}{ Heterogeneity factors } & \multirow[t]{2}{*}{ Coefficient } & \multirow[t]{2}{*}{ SE } & \multirow[t]{2}{*}{$Z$} & \multirow[t]{2}{*}{$\mathrm{P}$} & \multicolumn{2}{|c|}{$95 \% \mathrm{CI}$} \\
\hline & & & & & LL & UL \\
\hline \multicolumn{7}{|l|}{ Year } \\
\hline Univariate & 0.025 & 0.075 & 0.33 & 0.743 & -0.122 & 0.171 \\
\hline Multivariate & -0.192 & 0.074 & -2.61 & 0.009 & -0.337 & -0.048 \\
\hline \multicolumn{7}{|l|}{ Country } \\
\hline Univariate & -0.813 & 0.412 & -1.97 & 0.048 & -1.620 & -0.005 \\
\hline Multivariate & -0.526 & 0.345 & -1.53 & 0.127 & -1.202 & 0.149 \\
\hline \multicolumn{7}{|l|}{ Source of control } \\
\hline Univariate & 0.142 & 0.616 & 0.23 & 0.818 & -1.065 & 1.349 \\
\hline Multivariate & 0.013 & 0.347 & 0.04 & 0.970 & -0.666 & 0.693 \\
\hline \multicolumn{7}{|l|}{ Genotyping method } \\
\hline Univariate & -0.258 & 0.140 & -1.84 & 0.065 & -0.532 & 0.016 \\
\hline Multivariate & -0.534 & 0.182 & -2.94 & 0.003 & -0.890 & -0.177 \\
\hline
\end{tabular}

$\mathrm{SE}=$ standard error; $95 \% \mathrm{CI}=95 \%$ confidence interval; $\mathrm{LL}=$ lower limit; $\mathrm{UL}=$ upper limit
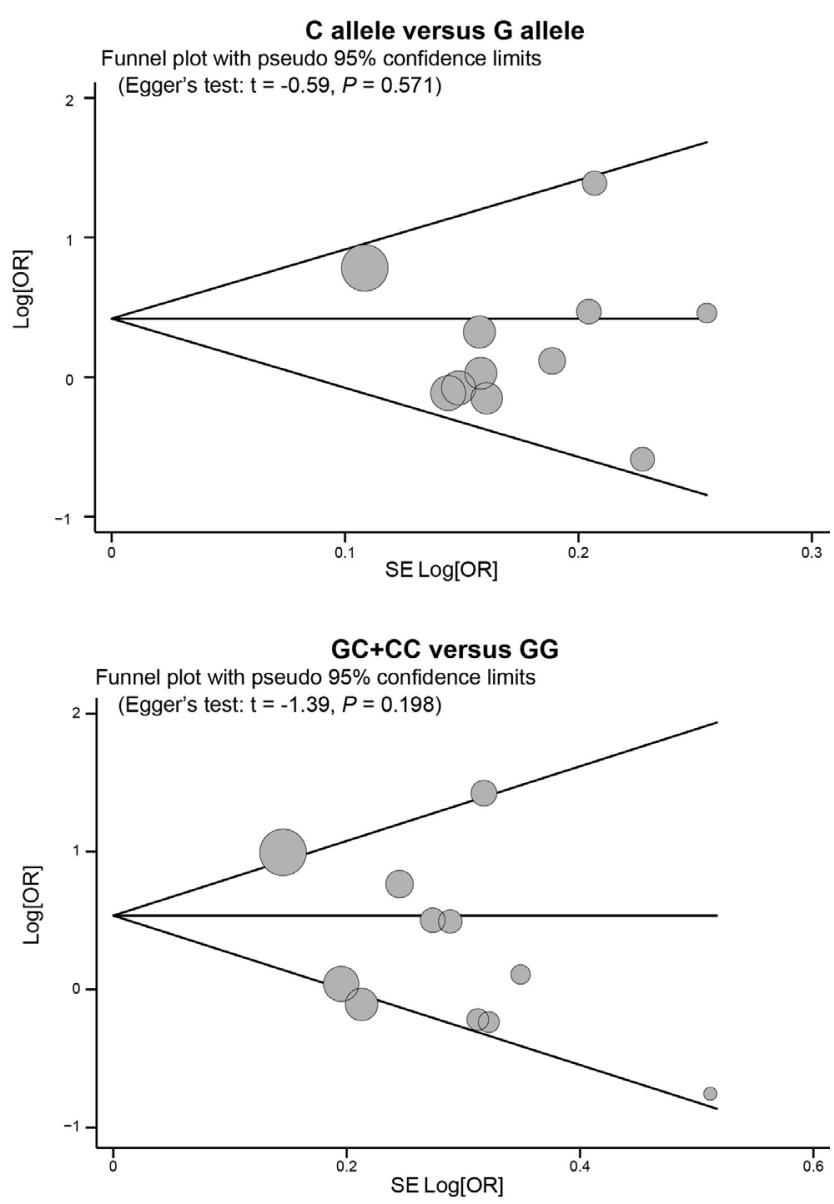

Figure 6. Funnel plot of publication biases for the association between the ADAM33 V4 polymorphism and asthma risk under the allele and dominant models. Each point represents a separate study for the indicated association. Log [OR], natural logarithm of OR. Horizontal line, magnitude of the effect. 


\section{DISCUSSION}

ADAM33, widely recognized as a type I transmembrane protein, is a member of the multifunctional a disintegrin and metalloproteinase ADAM family (Tripathi et al., 2011; Sharma et al., 2011). ADAM33 performs important functions during cell signaling, cell adhesion, cell fusion, and proteolysis, as well as in the activation of growth factors and Th2 cytokines (Reiss and Saftig, 2009). Many studies have shown that ADAM33 is expressed in asthmatic sub-epithelial fibroblasts and smooth muscle, but not in the respiratory epithelium under different circumstances and depending on nucleotide sequence (Holgate et al., 2006; Jie et al., 2009). Genetic variations in the $A D A M 33$ gene may result in abnormal changes in fibroblasts and bronchial smooth muscle cell functions, thereby inducing airway remodeling and airway hyper-responsiveness that is correlated with the development of airway inflammation (Jie et al., 2009; Lambrecht and Hammad, 2012). Therefore, ADAM33 genetic polymorphisms have been proposed to be involved in asthma pathogenesis and progression.

In the present meta-analysis, we evaluated the relationship between the ADAM33 V4 polymorphism and asthma risk. Based on our literature search, 8 independent case-control studies were included, for a total of 2128 asthma patients and 3134 healthy controls. Our meta-analysis results indicate that the ADAM33 V4 polymorphism is associated with an increased risk of asthma, suggesting that the V4 polymorphism may be a causative factor for the incidence of asthma. Although the exact function of $A D A M 33$ in the development of asthma is not fully understood, a potential explanation is that $A D A M 33$ is an important chemokine in the pathogenesis of asthma and gene mutations, and thus the expression level of ADAM33 is significantly correlated with susceptibility to asthma (Awasthi et al., 2011; Liang et al., 2013). Because heterogeneity can be clearly observed, we performed stratified analyses based on the studies' source of controls and genotyping method. Our subgroup analysis by source of controls revealed significant correlations between the $A D A M 33 \mathrm{~V} 4$ polymorphism and asthma risk in both population-based and hospital-based groups, indicating no significant differences in population selectivity. Further subgroup analyses also showed that the ADAM33 V4 polymorphism was correlated with an increased risk of asthma in the PCR-RFLP subgroup but not in the non-PCR-RFLP subgroup. These results indicate that genotyping method is a potential source of heterogeneity. In summary, our findings were consistent with those of previous studies demonstrating that the $A D A M 33 \mathrm{~V} 4$ polymorphism may be strongly linked to the development and progression of asthma. Thus, our results also confirm that the ADAM33 V4 polymorphism can be utilized as a biomarker for early diagnosis of asthma.

There were some limitations to this meta-analysis. First, our data may not have sufficient statistical power to estimate the correlation between the ADAM33 V4 polymorphism and asthma risk because of its relatively small sample size. Second, because meta-analysis is a retrospective method that may lead to subject selection bias, the reliability of our results may have been influenced. Third, our meta-analysis failed to obtain original data from the included studies, which may have limited the further evaluation of the potential roles of the ADAM33 genetic polymorphisms in asthma development. Notably, the inclusion criteria of cases and controls were not well-defined in all the included studies, and thus it is possible that our results were influenced by such irregularities. In conclusion, our meta-analysis revealed that the $A D A M 33 \mathrm{~V} 4$ polymorphism may contribute to asthma risk. Thus, the ADAM33 V4 polymorphism may be utilized as a biomarker for early diagnosis of asthma. However, further detailed studies are required to confirm our findings. 


\section{Conflicts of interest}

The authors declare no conflict of interest.

\section{ACKNOWLEDGMENTS}

We would like to thank all of our colleagues working in the Department of Laboratory Medicine, the General Hospital of Shenyang Military Region. Research supported by National Natural Science Foundation of China (Grant \#81072084 and \#81100869).

\section{REFERENCES}

Akinbami LJ, Moorman JE, Bailey C, Zahran HS, et al. (2012). Trends in asthma prevalence, health care use, and mortality in the United States, 2001-2010. NCHS Data Brief 1-8.

Awasthi S, Tripathi P, Ganesh S and Husain N (2011). Association of ADAM33 gene polymorphisms with asthma in Indian children. J. Hum. Genet. 56: 188-195.

Bijanzadeh M, Ramachandra NB, Mahesh PA, Mysore RS, et al. (2010). Association of IL-4 and ADAM33 gene polymorphisms with asthma in an Indian population. Lung 188: 415-422.

Blumenthal MN (2012). Genetic, epigenetic, and environmental factors in asthma and allergy. Ann. Allergy Asthma Immunol. 108: 69-73.

Chi XY, Xiao W, Wang XQ, Li Q, et al. (2012). Study on relationship between genetic polymorphisms of ADAM33 and susceptibility to bronchial asthma. Intern. J. Res. 32: 12-16.

Deloukas P, Matthews LH, Ashurst J, Burton J, et al. (2001). The DNA sequence and comparative analysis of human chromosome 20. Nature 414: 865-871.

Dupont WD and Plummer WD Jr (1990). Power and sample size calculations. A review and computer program. Control Clin. Trials 11: 116-128.

Hodgkinson LM, Wang L, Duncan G, Edwards DR, et al. (2010). ADAM and ADAMTS gene expression in native and wound healing human lens epithelial cells. Mol. Vis. 16: 2765-2776.

Holgate ST (2008). The airway epithelium is central to the pathogenesis of asthma. Allergol. Int. 57: 1-10.

Holgate ST, Davies DE, Powell RM and Holloway JW (2006). ADAM33: a newly identified protease involved in airway remodelling. Pulm. Pharmacol. Ther. 19: 3-11.

Howard TD, Postma DS, Jongepier H, Moore WC, et al. (2003). Association of a disintegrin and metalloprotease 33 (ADAM33) gene with asthma in ethnically diverse populations. J. Allergy Clin. Immunol. 112: 717-722.

Jie Z, Jin M, Cai Y, Bai C, et al. (2009). The effects of Th2 cytokines on the expression of ADAM33 in allergen-induced chronic airway inflammation. Respir. Physiol. Neurobiol. 168: 289-294.

Klein $\mathrm{T}$ and Bischoff R (2011). Active metalloproteases of the a disintegrin and metalloprotease (ADAM) family: biological function and structure. J. Proteome Res. 10: 17-33.

Knutsen AP and Slavin RG (2011). Allergic bronchopulmonary aspergillosis in asthma and cystic fibrosis. Clin. Dev. Immunol. 2011: 843763.

Lambrecht BN and Hammad H (2012). The airway epithelium in asthma. Nat. Med. 18: 684-692.

Lee JH, Park HS, Park SW, Jang AS, et al. (2004). ADAM33 polymorphism: association with bronchial hyperresponsiveness in Korean asthmatics. Clin. Exp. Allergy 34: 860-865.

Li HB, Xu GC, Gui LH, Feng XJ, et al. (2012). Association of the interactions between TGF-1 and ADAM33 gene with susceptibility and severity in childhood asthma. Cell. Mol. Immunol. 28: 640-644.

Liang S, Wei X, Gong C, Wei J, et al. (2013). A disintegrin and metalloprotease 33 (ADAM33) gene polymorphisms and the risk of asthma: a meta-analysis. Hum. Immunol. 74: 648-657.

Louis R, Schleich F, Corhay JL and Louis E (2012). Asthma: a complex disease determined by genetic and environmental factors. Rev. Med. Liege 67: 286-291.

Miyake Y, Tanaka K and Arakawa M (2012). ADAM33 polymorphisms, smoking and asthma in Japanese women: the Kyushu Okinawa Maternal and Child Health Study. Int. J. Tuberc. Lung Dis. 16: 974-979.

Peters JL, Sutton AJ, Jones DR, Abrams KR, et al. (2006). Comparison of two methods to detect publication bias in metaanalysis. JAMA 295: 676-680.

Qu S, Sun D, Wang Y, Zhang C, et al. (2011). Association of ADAM33 polymorphisms with childhood asthma in a 
northern Chinese population. Exp. Mol. Pathol. 91: 775-779.

Reiss K and Saftig P (2009). The "a disintegrin and metalloprotease" (ADAM) family of sheddases: physiological and cellular functions. Semin. Cell. Dev. Biol. 20: 126-137.

Sharma N, Tripathi P and Awasthi S (2011). Role of ADAM33 gene and associated single nucleotide polymorphisms in asthma. Allergy Rhinol. 2: e63-e70.

Stang A (2010). Critical evaluation of the Newcastle-Ottawa scale for the assessment of the quality of nonrandomized studies in meta-analyses. Eur. J. Epidemiol. 25: 603-605.

Su D, Zhang X, Sui H, Lu F, et al. (2008). Association of ADAM33 gene polymorphisms with adult allergic asthma and rhinitis in a Chinese Han population. BMC Med. Genet. 9: 82.

Tripathi P, Awasthi S, Prasad R, Husain N, et al. (2011). Association of ADAM33 gene polymorphisms with adult-onset asthma and its severity in an Indian adult population. J. Genet. 90: 265-273.

Tsicopoulos A, de Nadai P and Glineur C (2013). Environmental and genetic contribution in airway epithelial barrier in asthma pathogenesis. Curr. Opin. Allergy Clin. Immunol. 13: 495-499.

Zintzaras E and Ioannidis JP (2005). HEGESMA: genome search meta-analysis and heterogeneity testing. Bioinformatics 21: $3672-3673$. 